\title{
Design Analysis of a Mobile-Based Gait Analyzer
}

\author{
Adedotun O. Owojori, Ibukunoluwa A. Adebanjo, and Samson A. Oyetunji
}

\begin{abstract}
Considering a system capable of identifying abnormalities in people's walking conditions in real-time, simply by studying his/her walking profile over a short period of time is a phenomenal breakthrough in the field of biotechnology. Such abnormalities could be as a result of injury, old age, or disease termed gait which could be analyzed using the pressure mapping technology. Pressure points in the feet of an injured person as he/she walks is analyzed by sets of sensors (capacitive sensors) carefully design with a rectangular $5.1 \mathrm{~cm}$ by $2 \mathrm{~cm}$ parallel aluminium plate and placed on developed footwear with a uniform distance of $1 \mathrm{~cm}$ across the dielectric material. The output of the pre-processing stage gives varying values which are calibrated and sent to the microcontroller. All placed on a portable sized Printed Circuit Board (PCB) making it moveable from one place to another (that is, mobile), is the pre-processing circuit that converts measured or evaluated result to the transmittable signal through a Mobile Communication System which can be received on a Personal Computer (PC) in form of a periodic chat and/ or report. The result of the analysis is shown both in simulation and hardware implementation of the system
\end{abstract}

Index Terms - Gait, Capacitive Sensor, Biomedical Device, Arthritis

\section{INTRODUCTION}

In order to analyze the way human walk, we need to understand the terms gait and gait analysis. Gait can be defined as a manner in which humans and animals walk [1]. It is defined as the pattern of movement on foot which can be subdivided into steady and unsteady gait [2]. Gait analysis, however, is the systematic study of animals and human locomotion using the eye and the brain of observers, augmented by instruments for measuring body movement, body mechanics, (via the pressure point) and the activity of the muscles, to classify the degree of steadiness of either the animal or human.

According to [3], gait is highly individual and complex with many variables to be observed and measured. Such include kinematic (that is, displacement, velocity and acceleration etc.) and deformation parameters (that is, strain, curvature, and twist etc.) which are useful parameters noteworthy for dynamic response of human gait [4]. Similarly, the body mass index (BMI) gives a relationship between a patient's height and weight to form a metric which relates to the body dynamics. [5] and [6] also affirms accurate analyses of gait from the study of an individual's leg that is, the study of all parameters related to the leg.

[7] reviewed the different approaches for the recognition and analysis of gait, namely: image processing, floor sensors and sensors placed on the body. These devices were either grouped as non-wearable, inertial sensor-based and wearable systems.

The motivation of this research is based on the fact that physical (real-life) problems can be translated to electrical

Published on May 25, 2019

A. O. Owojori, I. A. Adebanjo and S. A. Oyetunji are with the Department of Electrical and Electronics Engineering, School of Engineering and Engineering Technology, Federal University of Technology, P.M.B. 704, signals/ parameter equivalents such as voltage, current, capacitance, inductance and other forms of transducers, either in analogue or digital form.

The presence of improved devices such as the Programmable Integrated Circuit (PIC) and Mobile Communication System interface which links a Personal Computer gives the opportunity to explore the vast resources of digital signal processing to achieve this [8]. The implementation of this system has proven that a microcontroller-based gait analyzer can be developed with the use of a capacitive sensor.

An accurate monitoring and evaluation system like this can be a solution to early detection or diagnosis of diseases and complication in a patient with respect to his/her walking condition [7].

\section{A. Pressure Mapping Technology}

The pressure mapping technology is one major method generally employed in gait analysis where pressure data are captured from the heel to the toe off of the person/patient as he/she walks. The device uses both the shoe and floor mat system [7], [9] and [10] in which when worn the initial values are read into the system and on a distance walk the change in pressure is observed [11].

The analogue signals (feedbacks) from the footswitches and the micro-optical sensors are smoothed and filtered in a subsystem which compares the obtained value with the threshold value before being fed for conversion to digital form and further processing within the microcontroller circuit [7].

This instantly provides a pressure map or distribution of different phases of the gait analysis on a planar surface in the form of a time graph. A positive feedback loop creates a threshold window and eliminates multiple triggering, which could occur during the transitional periods when the signal is changing. The software program is written specifically for the system to extract the relevant gait variables [4].

Further researches extend this method to a point were highspeed cameras having different interferometric setups are deployed for capturing dynamics of the patients [4]. In most cases, markers in the form of a no-battery power sensor which conducts the gait are deployed and monitored similar to the Kinect's virtual skeleton frame [10].

\section{B. Body Mass Index}

The body mass index (BMI) is a quantity which shows the relation between the weight and height of a patient. This is an important parameter that could give a better understanding of a patient's likelihood of having arthritis [12]. The BMI is simply obtained by taking the mass weight of a patient $(\mathrm{kg})$ on a weighing balance calculated in the relation below with the height $(\mathrm{m})$ measured with a rigid meter rule.

Akure, Ondo State, Nigeria (e-mail: aoowojori@futa.edu.ng; iaadebanjo@futa.edu.ng; saoyetunji@futa.edu.ng). 


$$
B M I=\frac{W}{h^{2}}
$$

In relations to the design intended to be carried out. The weight is proportional to the pressure applied by the patient on the developed capacitive sensor device. Therefore,

where

$$
\begin{gathered}
P=\frac{F}{A} \\
P=\rho g h
\end{gathered}
$$

$\mathrm{P}$ is the pressure $\left(\mathrm{N} / \mathrm{m}^{2}\right)$

$\mathrm{F}$ is the force applied (N)

A is the surface area of application $\left(\mathrm{m}^{2}\right)$

$\rho$ is the density of the material $\left(\mathrm{kg} / \mathrm{m}^{3}\right)$

$\mathrm{g}$ is the acceleration due to gravity $\left(\mathrm{ms}^{-2}\right)$

$\mathrm{h}$ is the height of the patient $(\mathrm{m})$

$\mathrm{W}$ is the weight of the patient $(\mathrm{kg})$

From this expression, it is possible to obtain the weight value.

The ranges of values of BMI as shown in Table I and Fig. 1 are also used in determining whether a patient is overweight, normal or under weigh and the values are valid for adults.

Similar to this is the study of the ground reaction force which gives a relationship between the body weight and duration of walking which helps to analyze a catastrophic failure or damages during walking [13].

TABLE I: THE VARIATION IN BODY MASS INDEX (BMI)

\begin{tabular}{ll}
\hline \hline Category & BMI \\
\hline Seriously Underweight & Less than 16.49 \\
\hline Underweight & $\begin{array}{l}\text { Between 16.5 } \\
\text { and 18.49 }\end{array}$ \\
\hline Normal & $\begin{array}{l}\text { Between 18.5 } \\
\text { and 24.99 }\end{array}$ \\
\hline Overweight & Between 25 and \\
\hline Obese & 29.99 \\
\hline \hline
\end{tabular}

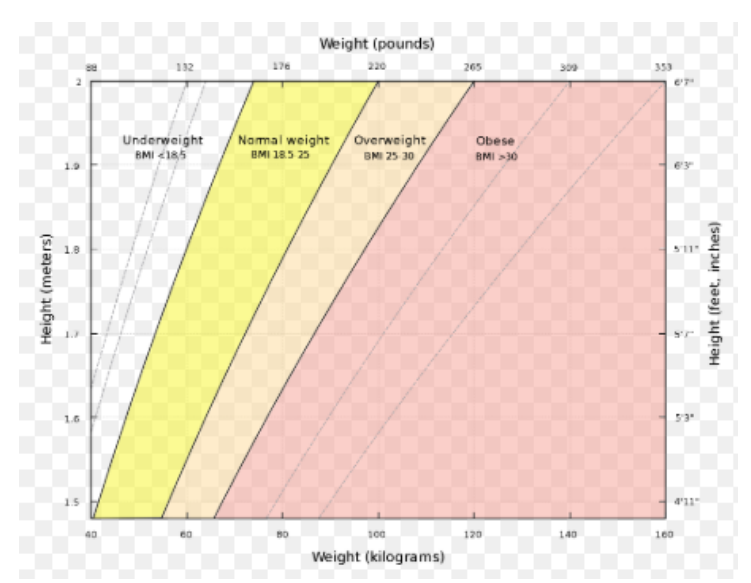

Fig. 1. The Variation in Body Mass Index (BMI).

These two concepts were used in the design of the gait analyzer, although with only some of the important parameters (vitals) considered.

Other affordable sensors that could be used for this application are the flex sensors [10], which shows significant directional characteristics such as the nominal resistance at $10 \mathrm{k} \Omega$ and when flexed or bent has resistance increased to about $40-50 \mathrm{k} \Omega$ with resistance tolerance of $\pm 30 \%$. Also, with a temperature range between -35 to 80 degree Celsius,
$4.4 \mathrm{~cm}$ by $0.25 \mathrm{~cm}$ in size, and $0.5-1 \mathrm{~W}$ power rating, and the foot-mat sensor. In order to make an easily affordable gait analyzer, a capacitive sensor is designed from a conductive aluminium material obtained from a metallic workshop at relatively low cost. These were cut into sizes intended to cover the phalanges, midfoot and the heel of the foot.

\section{Methodology}

In an attempt to visualize the overall system design or model design, a modular approach was used which links all the subsystems together from the sensor or transducer design to the overall unit design.

\section{A. Sensor Design}

The system requires the design of parallel plate capacitors with capacitance expressed below, of rectangular shape, separated with a dielectric which is foam. The rectangular 5.1 $\mathrm{cm}$ by $2 \mathrm{~cm}$ parallel aluminium plate capacitor is designed to store electric energy by electrostatic stress in the dielectric material. Basically, the dielectric material insulates the twoopposite plate from each other.

where

$$
\begin{aligned}
& C=\frac{\varepsilon A}{d} \\
& \varepsilon=\varepsilon_{0} \varepsilon_{r}
\end{aligned}
$$

$C$ is the capacitance of a capacitor (farad)

$A$ is the area of the capacitor plate $\left(\mathrm{m}^{2}\right)$ $\mathrm{d}$ is the dielectric distance between the plates $(\mathrm{m})$ $\varepsilon$ is the permittivity of the dielectric material

This equation shows that the capacitance of a parallel plate capacitor is inversely proportional to the dielectric distance between the plates, which is key to the formulation of the sensor attributes.

Also, from the expression below,

$$
\begin{gathered}
\mathrm{X}_{c}=\frac{1}{j \omega C} \\
\omega=2 \pi f
\end{gathered}
$$

where

$\mathrm{X}_{c}$ is the capacitive reactance of a capacitor (Ohms) $\omega$ is the angular frequency $(\mathrm{rad} / \mathrm{sec})$

It could be deduced that the capacitive reactance is a function of frequency, that is, as capacitance increases, frequency decreases.

where

$$
C=\frac{K}{d}
$$

\section{$\mathrm{K}$ is expressed as $\varepsilon_{0} \varepsilon_{\mathrm{r}} \mathrm{A}$}

The dielectric material is one major element of a capacitor. There are several types of dielectric materials ranging from air, paper, glass, with varying relative permittivity $\left(\varepsilon_{\mathrm{r}}\right)$. In this design, the foam was used as the dielectric material placed between the conductive plates. This allows the pressure applied to the material to regain its initial position (elastic property). The foams dielectric and the capacitive plate area were assumed constant.

From the equations below it is possible to express the relations between weight and capacitance of the sensor

$$
\begin{aligned}
& Q=C V \\
& V=E d
\end{aligned}
$$


where

$$
\begin{gathered}
C=\frac{\varepsilon_{0} \varepsilon_{r} A}{d} \\
V=\frac{W}{Q} \\
W=\frac{F d}{V} \\
Q=\frac{F d}{V} \\
\frac{F d}{V}=\frac{\varepsilon_{0} \varepsilon_{r} A V}{d} \\
F=\frac{\varepsilon_{0} \varepsilon_{r} A V^{2}}{d^{2}} \\
F=\frac{C V^{2}}{d} \\
F=\frac{K V^{2}}{d^{2}} \\
F=m g
\end{gathered}
$$

$\mathrm{E}$ is the electric field intensity $(\mathrm{V} / \mathrm{m})$

$\mathrm{V}$ is the electric potential difference $(\mathrm{V})$

$Q$ is the quantity of charge stored (C)

The sensor capacitance value was monitored with a digital multimeter in the picofarad range as a known weight is applied, establishing its relations with variation in the dielectric distance. This forms the first phase of the model design after which the sensor is linked with the main circuit.

The selection of cable is important since the design should allow the mobility of the patient. The cable chosen is lightweight, $0.2 \mathrm{~cm}$ diameter stranded cable, which was used to tap out capacitance variation (signal) to the main circuit.

\section{B. Multivibrator Design}

The circuit design entails the manipulation of the signals obtained from the capacitive sensor to carry out the desired tests. This forms the second phase of the model design. The capacitive sensor makes up a total of 16: 8 on each developed footwear labelled channel 1 to 8 as shown in Fig. 3. To achieve the purpose of measuring variations from the capacitive sensor, a frequency pulse generator 556-timer or multivibrator was used as shown in Fig. 2.

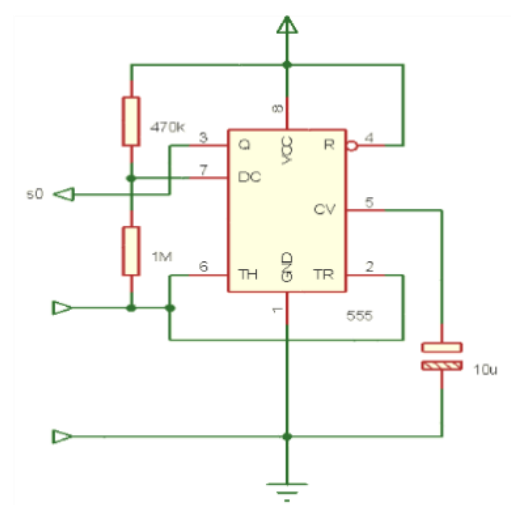

Fig. 2. 556 multivibrator circuit in astable mode.
The 556-timer circuit is an integrated circuit (IC) chip which generates a pulse wave output used mostly in clocking applications. The 556 IC is designed to accommodate two 555 ICs in one with a common source and ground. Each 556 ICs, therefore, was able to accommodate 2 capacitive sensors, which in turn helps reduce the circuit structure and cost. The 14-pin mini dual-in-line (DIL-14) 556 timer was connected in an astable mode with each capacitive sensor connected to the threshold and trigger terminals of the timer circuit.

The values of resistors $R_{1}$ and $R_{2}$ were taken within the range of $k \Omega$ and $M \Omega$, such that $R_{2} \sim 100 R_{1}$. Due to the $p F$ range of the capacitance value $\mathrm{C}_{1}$ obtained from the sensor, the resistor $R_{1}$ and $R_{2}$ were chosen to be $10 \mathrm{k} \Omega$ and $1 \mathrm{M} \Omega$ respectively. This assumption was made in order to view the output variation of the multivibrator on the oscilloscope with a clearer view at a lower frequency of $7 \mathrm{kHz}$ at $300 \mathrm{pF}$. The astable multivibrator operates on the basis of this equation:

$$
\begin{gathered}
f=\frac{1.4}{\left(R_{1}+2 R_{2}\right) C_{1}} \\
T=\frac{1}{f}
\end{gathered}
$$

Terminals 3 and 11 are connected to the ground through 10 $\mathrm{uF}$ capacitor. The output pulses were then obtained from terminals 9 and 5, having a maximum output current of 20 mA.

\section{Multiplexer Design}

The individual frequency pulse varies with varying capacitance value $\mathrm{C}_{1}$ attached to each branch of the 556 multivibrator circuit, therefore generating an analogue signal. In order to process each of the 16 analogue output signals (channels) from the multivibrator going into the (PIC16F877A) microcontroller, a multiplexer unit is needed.

The HEF4051BP IC is an 8-channel analogue multiplexer used for this application which controls the 16 channel analogue inputs from the 556 multivibrator. The device takes in ' $n$ ' inputs and gives out only one output based on a number of selector(s). 


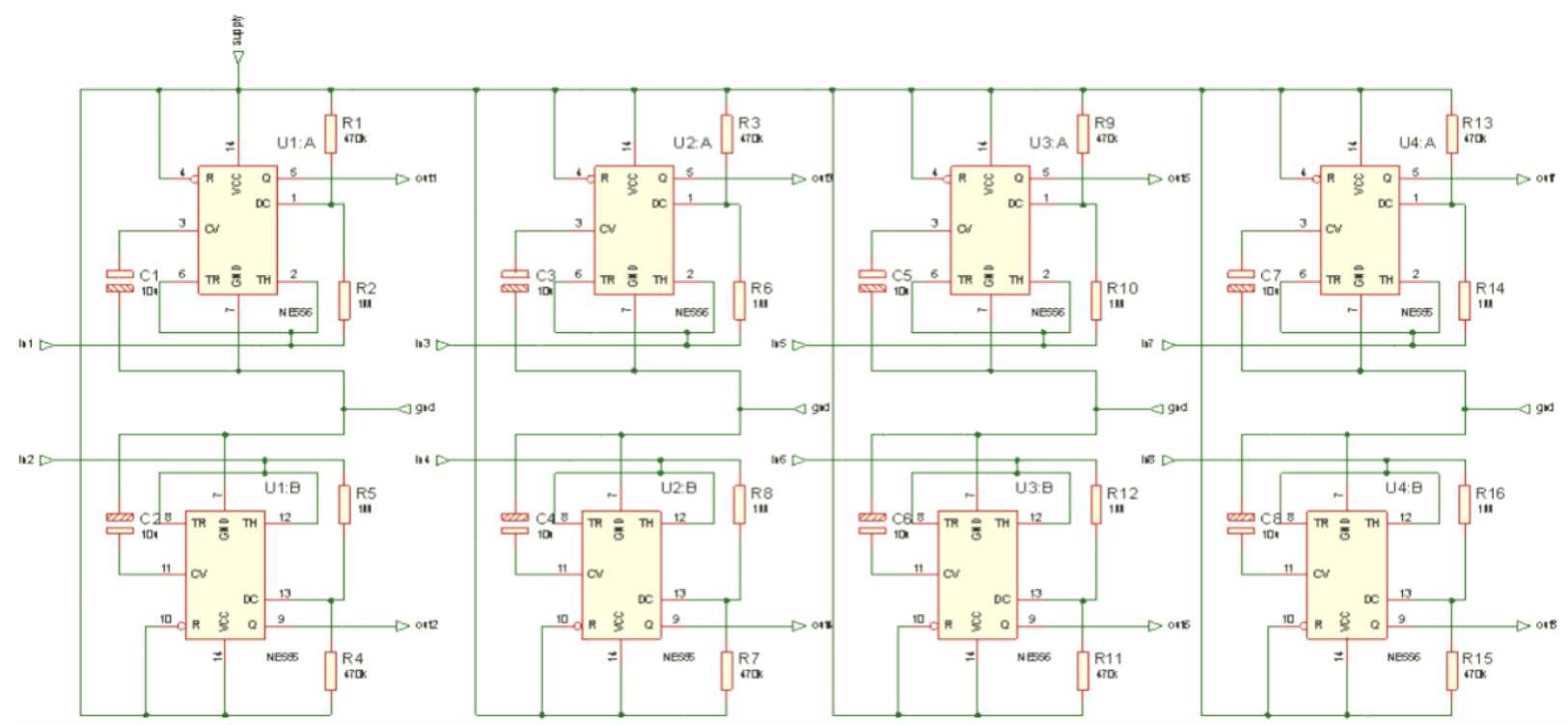

Fig. 3. 556 multivibrator configuration for 8 channel sensors.

The 16 input signals are split into LEFT and RIGHT, then passed into two 8 channel analogue multiplexer (HEF 4051). The device has three binary control inputs $(\mathrm{A}, \mathrm{B}, \mathrm{C})$ linked with the selector and an inhibit input (INH). The external multiplexer circuit relieves the PIC microcontroller of the 16 input analogue signal channels.

The selectors operate based on the principle: $\mathrm{s} \sim\left(\mathrm{s}_{\mathrm{k}-1}, \mathrm{~s}_{\mathrm{k}-2} \ldots\right.$ $\mathrm{s}_{0}$ ); which is a function of the input signal expressed as $\mathrm{N} \sim 2^{\mathrm{k}}$, where $\mathrm{N}$ is the total input signals entering into the multiplexer. Therefore, with the channel 1-8, designated $\mathrm{x} 0$ - $\mathrm{x} 7$, the 8-1 multiplexer requires 3 selectors: $s \sim \mathrm{s}_{2}, \mathrm{~s}_{1}, \mathrm{~s}_{0}$, and gives out outputs corresponding to the LEFT and RIGHT leg per clock phase as shown in Table II.

The inhibit input of the multiplexer is sourced from the $+\mathrm{Vcc}$, while the selector ports $\mathrm{s}_{0}, \mathrm{~s}_{1}, \mathrm{~s}_{2}$ are clock pulses generated from a 555 multivibrator circuit having $\mathrm{R}_{1}$ and $\mathrm{R}_{2}$ to be $10 \mathrm{k} \Omega, 1 \mathrm{M} \Omega$ and $\mathrm{C}_{1}$ having varying values to set frequency offset of $7 \mathrm{kHz}, 3.5 \mathrm{kHz}$ and $1.75 \mathrm{kHz}$. The Circuit layout of the system without the connection of microcontroller is illustrated in Fig. 4. Alternatively, the selector pulses could be generated from a PIC microcontroller port to drive the multiplexer.

TABLE II: SELECTOR CONFIGURATION FOR A MULTIPLEXER CIRCUIT

\begin{tabular}{lllll}
\hline Channels & $\mathrm{s}_{2}$ & $\mathrm{~s}_{1}$ & $\mathrm{~s}_{0}$ & $\mathrm{Y}$ \\
\hline Brown & 0 & 0 & 0 & $\mathrm{x} 0$ \\
\hline Green & 0 & 0 & 1 & $\mathrm{x} 1$ \\
\hline White & 0 & 1 & 0 & $\mathrm{x} 2$ \\
\hline Grey & 0 & 1 & 1 & $\mathrm{x} 3$ \\
\hline Purple & 1 & 0 & 0 & $\mathrm{x} 4$ \\
\hline Yellow & 1 & 0 & 1 & $\mathrm{x} 5$ \\
\hline Black & 1 & 1 & 0 & $\mathrm{x} 6$ \\
\hline Blue & 1 & 1 & 1 & $\mathrm{x} 7$ \\
\hline \hline
\end{tabular}

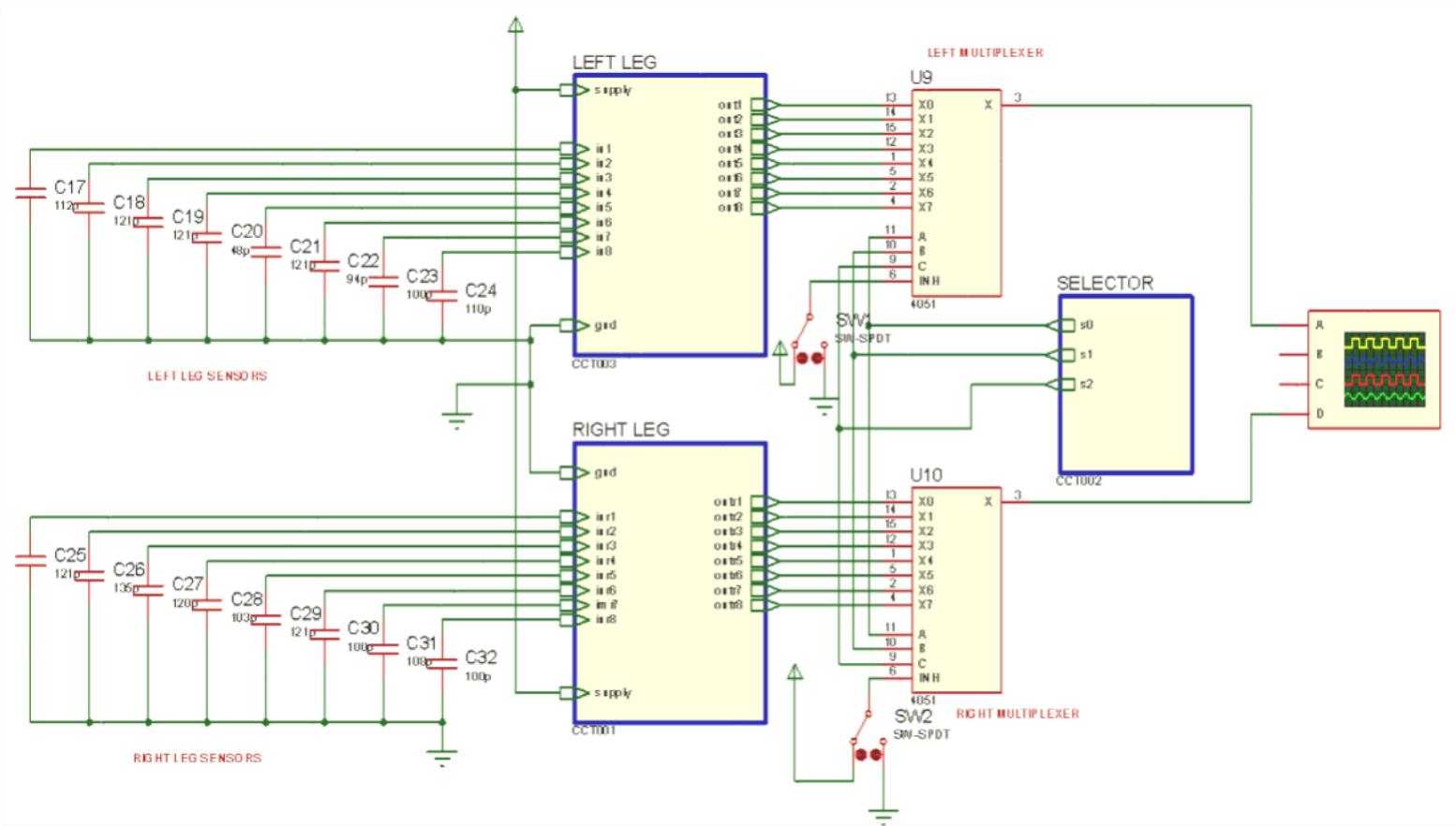

Fig. 4. Circuit layout of the system without the microcontroller connected. 


\section{PIC Microcontroller Design}

The microcontroller (embedded system) is a self-contained computer which incorporates all the basic components of a personal computer on a much smaller scale. The microcontroller allows the digitization of analogue signals using the analogue-to-digital converter (ADC) as explained in [8].

The presence of 8 analogue input pins on a microcontroller AN0, AN1... AN7 which are pin 2, 3, 4, 5, 7, 8, 9, 10 on the 40 pin 16F877A PIC makes it useful to carry out only a maximum of 8 channel analogue processing [14]. Although, two analogue output terminals from the multiplexer are required for the design, containing the 16 capacitive sensor channels to be fitted into the microcontroller input terminal as shown in Fig. 5.

A voltage reference $\left(\mathrm{V}_{\text {ref }}\right)$ of 5 volts was set for the ADC conversion process having a choice bit $\mathrm{B}$, based on the expression:

$$
C_{\text {val }}=\frac{\left(v_{\text {in }} \times V_{\text {ref }}\right)}{\left(2^{B}-1\right)}
$$

The PIC microcontroller requires voltage between $5-12 \mathrm{~V}$ supply to operate. The peripheral circuits attached to the microcontroller include the voltage regulator, crystal oscillator, capacitors and pull up resistor. The input voltage into the circuit design is chosen to be $9 \mathrm{~V}$. A voltage regulator is added to the circuit to help stabilize the voltage level to $5 \mathrm{~V}$ which is made available to drive the PIC microcontroller, multiplexers, and the 556 multivibrator. Smoothing capacitors are also connected to the input and output terminals of the voltage regulator. External crystal oscillators with two capacitors are fitted to CLKIN and CLKOUT pins of the microcontroller [15]. The oscillator frequency used for the design is $8 \mathrm{MHz}$ which gives an idea of the system accuracy and instruction execution time.

An algorithm was developed to extract the 16-channel sensor values on the microcontroller in comparison with some threshold values which were processed to determine the walking condition of a patient. This was first achieved via simulation using the Proteus 8 Professional schematic software tool and Microchip MPLAB IDE (running C programming), while for the real-life implementation the usbpicprog 0.4.2 software was used to deploy the HEX or $\mathrm{COF}$ files generated from the MPLAB to the microcontroller PIC16F877A.

The algorithm further extends interfacing many other devices such as GSM module, external memory/ card reader, wireless module and Bluetooth module depending on the range of application and cost.

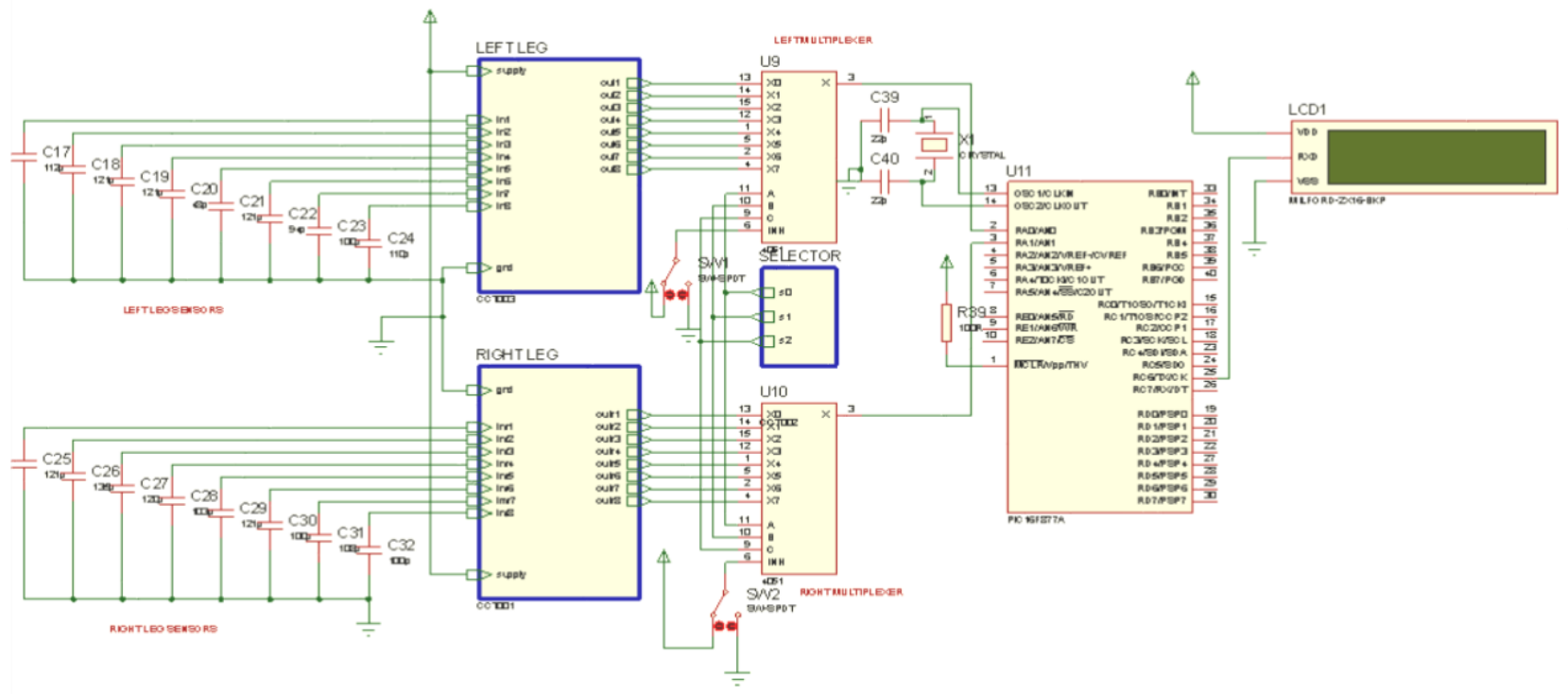

Fig. 5. Overall Circuit layout of the System

\section{RESULTS AND ANALYSIS}

An abnormality in a patient's walking condition may be as a result of injury or disease [16] reflected on the foot sensor depicted as variation in capacitance value. The footwear capacitive sensor is shown in Fig. 6 highlighting the sensor alignment and connection.

The designations of channels are given as:

\section{Designation:}

Brown - channel 1

Green - channel 2

White - channel 3

Grey - channel 4

Purple - channel 5

Yellow - channel 6

$$
\begin{aligned}
& \text { Black - channel } 7 \\
& \text { Blue - channel } 8
\end{aligned}
$$

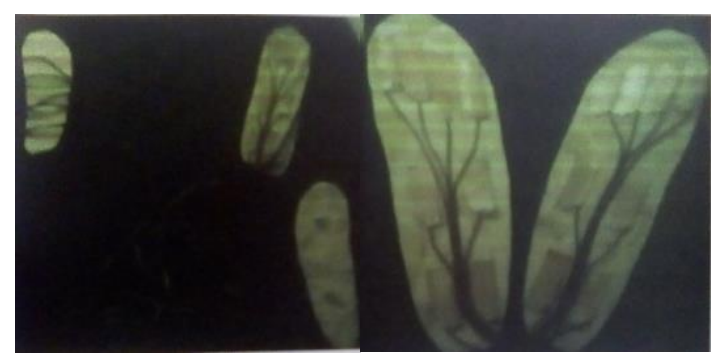

Fig. 6. Capacitive Sensor Plate representation.

with variations in the pico-Farad range when measured with a multimeter before incorporating it into the overall circuit design. 
Once a patient is undergoing biomedical assessment, it is often essential to study how weight affects its gait. Table III and IV gives a measured relationship between two sampled weight $65 \mathrm{~kg}$ and $75 \mathrm{~kg}$ for both left and right legs in comparison with the sensor initial capacitance reading which shows that an increase in weight will cause more pressure to be exerted on the capacitive sensor hence causing an increase in capacitance.

TABLE III: COMPARISON OF THE CAPACITANCE VALUES IN PF OF THE LEFT LEG OF TWO SAMPLED WEIGHT AS AGAINST INITIAL VALUES

\begin{tabular}{llccc}
\hline S/N & Channels & $\begin{array}{c}\text { Initial } \\
\text { Value (pF) }\end{array}$ & $\begin{array}{c}\text { Observed } \\
\text { Value }(\mathrm{pF}) \\
\text { at 75kg } \\
\text { weight }\end{array}$ & $\begin{array}{c}\text { Observed } \\
\text { Value } \\
(\mathrm{pF}) \text { at } \\
65 \mathrm{~kg} \\
\text { weight }\end{array}$ \\
\hline 1 & Brown & 85 & 112 & 109 \\
\hline 2 & Green & 91 & 121 & 113 \\
\hline 3 & White & 95 & 121 & 118 \\
\hline 4 & Grey & 36 & 48 & 38 \\
\hline 5 & Purple & 80 & 121 & 119 \\
\hline 6 & Yellow & 80 & 94 & 83 \\
\hline 7 & Black & 76 & 100 & 79 \\
\hline 8 & Blue & 83 & 110 & 100 \\
\hline \hline
\end{tabular}

TABLE IV: COMPARISON OF THE CAPACITANCE VALUES IN PF OF THE RIGHT LEG OF TWO SAMPLED WEIGHT AS AGAINST INITIAL VALUES

\begin{tabular}{llccc}
\hline \hline S/N & Channels & $\begin{array}{c}\text { Initial } \\
\text { Value }(\mathrm{pF})\end{array}$ & $\begin{array}{c}\text { Observed } \\
\text { Value }(\mathrm{pF}) \\
\text { at 75kg } \\
\text { weight }\end{array}$ & $\begin{array}{c}\text { Observed } \\
\text { Value } \\
(\mathrm{pF}) \text { at } \\
65 \mathrm{~kg} \\
\text { weight }\end{array}$ \\
\hline 1 & Brown & 78 & 121 & 100 \\
\hline 2 & Green & 90 & 135 & 99 \\
\hline 3 & White & 93 & 120 & 112 \\
\hline 4 & Grey & 84 & 103 & 101 \\
\hline 5 & Purple & 79 & 121 & 100 \\
\hline 6 & Yellow & 80 & 100 & 92 \\
\hline 7 & Black & 82 & 108 & 106 \\
\hline 8 & Blue & 83 & 100 & 98 \\
\hline \hline
\end{tabular}

By definition, there is an inverse relationship between the capacitance value and dielectric distance between the plates which was satisfied.

The foam (dielectric material) used was capable of returning back to its initial distance at nearly the same initial capacitance value during sensor testing. To cater for thresholds used in the software section of the system (PIC algorithm) the extreme capacitance parameters were observed for both left and right legs depicted in Table $\mathrm{V}$

TABLE V: EXTREME CAPACITANCE VALUES (CN) FOR THE LEFT AND RIGHT LEG

\begin{tabular}{llcc}
\hline \hline S/N & Channels & $\begin{array}{c}\text { Left Leg } \\
\text { Observed } \\
\text { Value }(\mathrm{pF})\end{array}$ & $\begin{array}{c}\text { Left Leg } \\
\text { Observed } \\
\text { Value }(\mathrm{pF})\end{array}$ \\
\hline 1 & Brown & 121 & 122 \\
\hline 2 & Green & 121 & 135 \\
\hline 3 & White & 126 & 120 \\
\hline 4 & Grey & 48 & 147 \\
\hline 5 & Purple & 142 & 128 \\
\hline 6 & Yellow & 94 & 100 \\
\hline 7 & Black & 153 & 108 \\
\hline \hline
\end{tabular}

The connection in Figure 4 illustrates the introduction of a multiplexer circuit with selectors which helps to pick signal peaks from the capacitive sensor circuit via the 556 multivibrator for both left and right legs. The resultant output of the multiplexer circuit is given in Fig. 7.

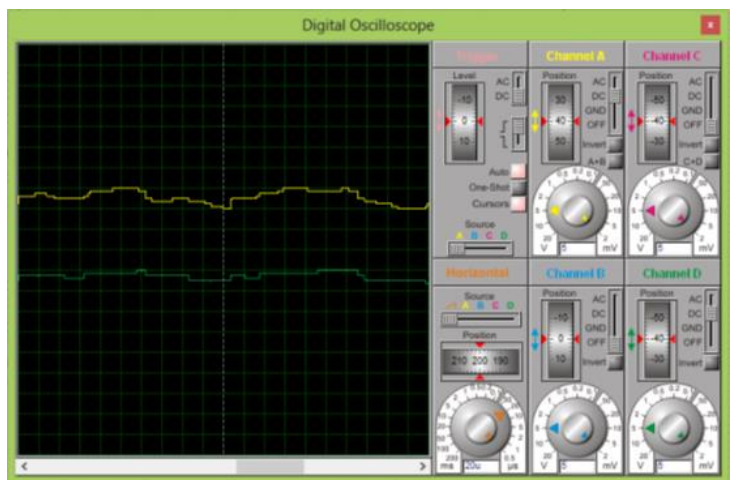

Fig. 7. Signal Characteristics for both Left and Right Legs

The same signal was viewed in Fig. 8 shows a comparison of the channels with one of the selector clock pulse on Proteus 8 Professional schematic software. Calibration of the system was carried out on the microcontroller during the simulation process by specifying the thresholds, sampling time, classifications vis a vis the abnormalities.

Common walking abnormalities considered for this device are:

a. Pain on the left leg

b. Pain on the right leg

c. Pain on the forefoot of the two legs (left and right)

d. Pain on the hind of the foot

e. Pain at the right side of any given leg

f. Pain at the left side of any given leg

The hardware, on the other hand, was implemented on a printed circuit board (PCB) as shown in Fig. 9 having the system algorithm transferred to the microcontroller unit via a programmer and usbpicprog 0.4.2 software.

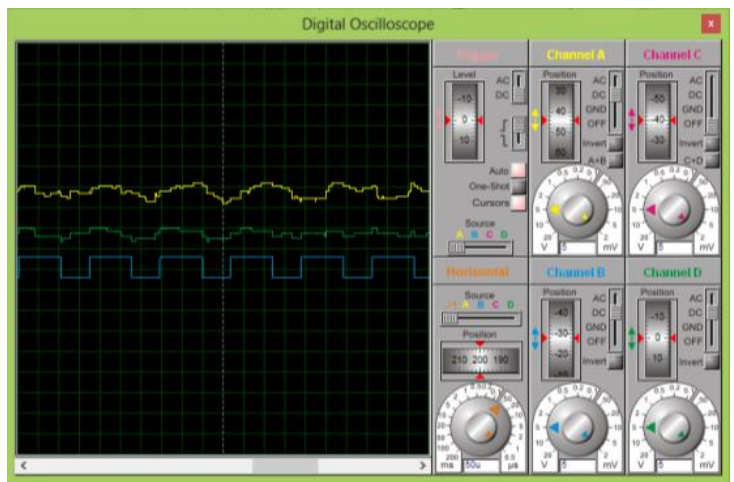

Fig. 8. Signal Characteristics with selector input 


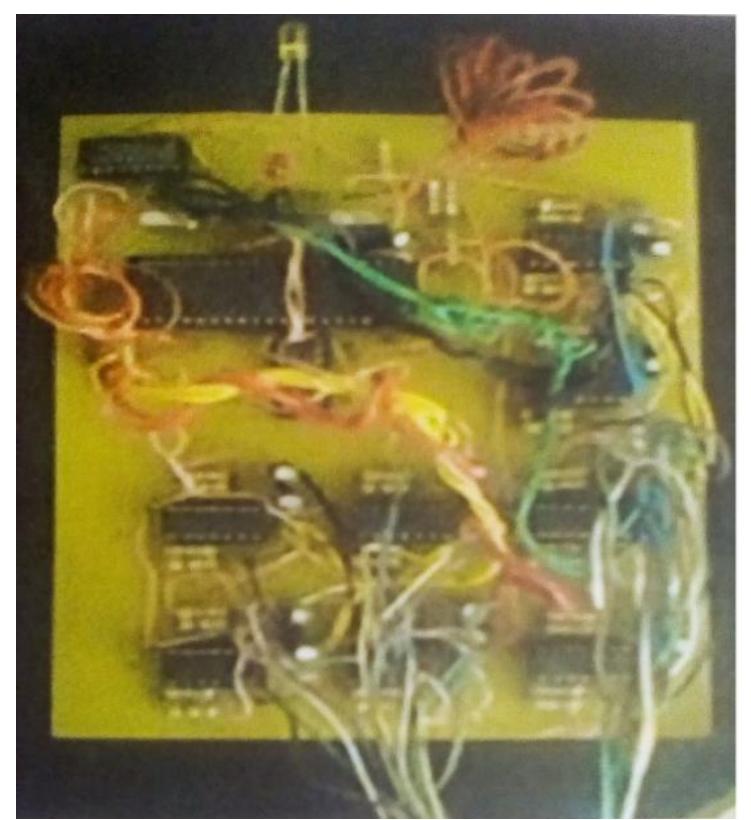

Fig.9. PCB Hardware Layout of the System

Other peripherals of the PIC16F877A such as TX, RX and display terminal interfaces are included to establish the workability of the system.

\section{CONCLUSION}

Gait analysis can be viewed beyond mere observation, pointing to the fact that physical behaviour can be characterized by an electronic equivalent component or circuit. The analysis of such a system has given an idea of how sensors are developed (Capacitive sensors) and incorporated into a system.

Depending on the area of pain the patient tends to exert more pressure on the area of less pain, hence causing an increase in capacitance value to be read in relations to the set threshold. Accumulation of such, with the help of the calibration within the microcontroller, can vividly give the walking profile of the patient. The overall system design was reduced to modular units which aid the understanding and design concepts of each subsystem.

First converting the passive component to influence the electrical quantity (frequency) then, with the help of a digital device, process the data. The microcontroller unit also serves as a reconfigurable unit, where updates on the sophistication of the device functionality can be sent without changing any physical (hardware) component.

The scope of the design was limited to the abnormalities considered, hence giving room for further holistic calibration of human gait such as steady and unsteady gait, which system design can be placed in tandem with recent technology in the pressure mapping system.

\section{ACKNOWLEDGEMENT}

The authors appreciate Labcenter Electronics, Microchip MPLAB and usbpicprog, for the accessible use of Proteus Design Suite 8.4 software, MPLAB IDE for validating the CCodes generated via simulation and usbpicprog 0.4.2, for easy deployment of HEX code into the real-life microcontroller.

\section{REFERENCES}

[1] M. Whittle. (2003). Gait Analysis an Introduction. Oxford, England: Butterworth \& Co (Publishers) Ltd.

[2] M. R. Hawes, D. Sovak. (1994). Quantitative Morphology of Human Foot in a North- American Population Ergonomics. p37

[3] S. Hirokawa, K. Matsumara. (1987). Gait Analysis using a Measuring Walkway for Temporal and Distance Factor. p 25

[4] Y. Fu, R. M. Groves, G. Pedrini and W. Osten (2007). Kinematic and deformation parameter measurement by spatiotemporal analysis of an interferogram sequence. Applied Optics, Optical Society of America. 46(36). Pp $8645-8655$

[5] R. A. Brand. (1987). Biomechanics Contribution to Clinical Orthopedic Assessments. Iowa Orthopedic Journal, pp 61-64

[6] R. A. Brand, R. D. Crowninshield. (1981). Comment on Criteria for Patient Evaluation Tools. Journal of Biomechanics, p 655

[7] A. Muro-de-la-Herran, B. Garcia-Zairain and A. Mendez-Zorrilla. (2014). Gait Analysis Methods: An Overview of Wearable and NonWearable Systems, Highlighting Clinical Applications. Open Access Journal of Sensors. Pp 3362-3394

[8] A. O. Owojori, T. O. Otunniyi, E. O. Ogunti. (2015). Digital Front-End for Software Defined Radio Wideband Channelizer. Communications on Applied Electronics 1(6) pp 25-35

[9] D. G. E. Robertson, G. E. Caldwell, J. Hamill. (2004). Research Methods in Biomechanics. International Journal of Sports Physiology and Performance $2^{\text {nd }}$ edition.

[10] B.A. Mahmood (2015). Lower Body Gait Analysis through Real Time Gait Parameter Measurements using Kinect. Masters Thesis, Electrical and Computer Engineering. The State University of New Jersey

[11] L. E. Larsson, P. Oldenrick, B. Sandlund. (1980). The phases of the stride and their interaction in human gait. pp 107- 112 .

[12] G. Eknoyan. (2008). The Average Man and Indices of Obesity. pp 4751

[13] Akhtaruzzaman, R. Khan, A. A. Shafie. (2016). Gait Analysis: Systems, Technologies, and Importance. Journal of Mechanics in Medicine and Biology. 16(7) pp 1630003-1 - 1630003-45

[14] M. P. Bartes. (2008). Programming 8- bit PIC Microcontroller in C. Microchip Technology Inc., pp 4- 50

[15] J. A. Paradiso, K. Hsiao, A. Y. Benbasat, and Z. Teegarden. (2000). Design and implementation of expressive footwear. IBM Systems Journal. 39(3) pp 511- 529

[16] J. Perry. (1985). Normal and Pathological Gait Function, in Atlas of Arthotics. Slack Inc. pp $76-111$

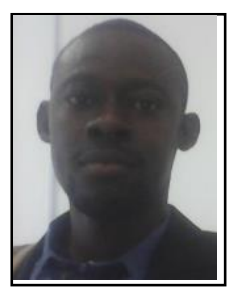

Adedotun O. Owojori received his B. Eng. and M. Eng. degrees from the Federal University of Technology, Akure, (FUTA), Ondo State, Nigeria, in 2011 and 2015 respectively. He is currently pursuing a PhD degree at the Federal University of Technology, Akure, (FUTA) where he joined as an academic staff in 2016. His current research interests include modelling and control of electronic devices and signal processing for software defined radio applications. He has three published articles (First Author and Co-Author): Digital Front-End for Software Defined Radio Wideband Channelizer (New York, USA: Communications on Applied Electronics, 2015), Low Complexity Farrow Differential Channelizer Algorithm. (New York, USA: Communications on Applied Electronics, 2015), Comparative Analysis of Farrow Fractional Structure Rate Converter. (New York, USA: Communications on Applied Electronics, 2015) Engr. Owojori is a member of ISMN, IEEE, NSE, COREN professional societies.

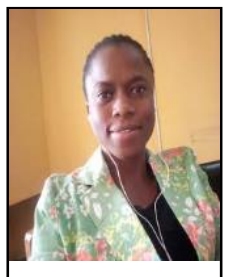

Ibukunoluwa A. Adebanjo received her B. Eng. and M. Eng. degrees from the Federal University of Technology, Akure, (FUTA), Ondo State, Nigeria, in 2010 and 2016 respectively. She is currently pursuing a $\mathrm{PhD}$ degree at the Federal University of Technology, Akure, (FUTA) where she joined as an academic staff in 2016. Her current research interests include modelling and control of electronic devices, and optical communication system designs and applications. Published articles (First Author and Co-Author): Single Carrier Frequency Domain Equalization with Space-Time Trellis Codes (Scientific Research, Communications and Network 2017), Engr. Adebanjo is a member of IEEE, NSE, COREN professional societies. 


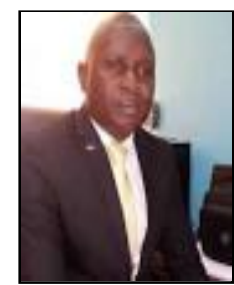

Samson A. Oyetunji received his B. Eng. degree from University of Ilorin, Kwara State, Nigeria, M. Eng., and $\mathrm{PhD}$ degrees from University of Benin, Benin City, in 2011 and 2015 respectively. He is an academic staff at Federal University of Technology, Akure, (FUTA). His research area includes design of electronic devices, optical communication systems and signal processing for software defined radio applications. Dr Oyetunji is a member of COREN professional societies. 